\title{
Steady State Mathematical Model of Test-Rig for the Validation of Experimental Temperature-Resistance Relationship of Temperature Sensing Fabric
}

\author{
Muhammad Dawood Husain $^{1 \mathrm{a}}$, Shenela Naqvi ${ }^{1 \mathrm{~b}}$, Muhammad Owais Raza Siddiqui ${ }^{1 \mathrm{c}}$, \\ Richard Kennon ${ }^{2}$
}

RECEIVED ON 17.08.2020, ACCEPTED ON 05.05.2021

\begin{abstract}
Continuous measurement of temperature profiles on the human body surface provides handy information for the diagnosis and as a beneficial guide to take appropriate action. A textile based Resistance Temperature Detector (RTD) has been reported recently, which could be exploited to monitor the temperature of human body over extended period of time. For the purpose of calibrating these textile based sensor, a tailor-made test rig has been developed. The working principle of this sensing fabric is the same as the RTD i.e. change in resistance because of change in temperature. Validation of experimental results by modelling was one of the prime objectives of this study. This paper reports the steady state mathematical model of the test rig components, by the application of fundamental heat transfer principles. It was concluded that the temperature varies linearly across the thickness of textile based temperature sensor in a rig setting while the temperature of the sensing element of textile based temperature sensor could be approximated by knowing its exact position within the fibrous structure. This input would be helpful for the calibration purpose of the sensor samples in an improved manner and to circumvent the individual testing and repetition of experiments on a test rig.
\end{abstract}

Keywords: Temperature Sensing Fabric, Sensing Element, Temperature-Resistance Relationship; Human Body Temperature, Steady-State Modelling, Machine-Knitting

\section{INTRODUCTION}

$\mathrm{I}$ $\mathrm{n}$ order to improve the patient's quality of life and lower the healthcare cost by reducing hospitalizations, number of research studies has been carried out in recent years; towards the development of Wearable Health Monitoring Systems (WHMS) for continuous monitoring of human body vital signs over extended periods of time [1-3]. To acquire the body signals, a sensing platform adjacent to the body is required. Textiles can offer a comfortable, flexible platform for the embedding of sensing functions; therefore development of sensing fabric or the textile based sensors has been the key fabric investigative area within the domain of WHMS [4-6].

Vital signs are measurements of the physiological condition of the human body and reveal the body's ability to regulate body temperature, maintain blood flow and oxygenate body tissues [7]. Each vital sign has its respective role in diagnosis and control of the disease. In standard medical settings, the most commonly measured vital signs are temperature, respiratory activity, Electrocardiography (ECG) and blood pressure. The human body core temperature is an essential gauge of the physical condition of the human body. Only few degrees deviation $\left( \pm 3.5^{\circ} \mathrm{C}\right)$,

\footnotetext{
${ }^{1}$ Department of Textile Engineering, NED University of Engineering and Technology, Karachi, Sindh, Pakistan. Email: ${ }^{\text {} d a w o o d @ ~ n e d u e t . e d u . p k, ~(C o r r e s p o n d i n g ~ A u t h o r), ~}{ }^{\mathrm{b}}$ shenelanaqvi@neduet.edu.pk, ${ }^{\mathrm{c}}$ orazas@neduet.edu.pk. ${ }^{2}$ School of Materials, The University of Manchester, Manchester, UK. Email: richard.kennon @ manchestor.ac.uk This is an open access article published by Mehran University of Engineering and Technology, Jamshoro under CC BY 4.0 International License.
} 
from the average core body temperature i.e. $37^{\circ} \mathrm{C}$, can results in the impairments and loss to the human body $[8,9]$.

Within the context of WHMS, preceding research has mainly concentrated on the development of sensing fabric for the measurement of respiratory and electrocardiography signals [10-17]. For the acquisition of temperature signals of the human body, investigators have predominantly counted on off-theshelf available temperature sensors, such as temperature-measuring ICs and thermistors [18-22]. The literature review has demonstrated that the development of textile based sensors for temperature measurement of human body has been insufficiently covered in some isolated studies [23-28].

In order to bridge this research gap a detailed study has been performed towards the development of dedicated textile based temperature sensor. The design and manufacturing of Temperature Sensing Fabric (TSF); the development of customized rig along with detailed experimentation for the calibration purpose of TSF; and effect of humidity and mechanical movement on the performance of TSF have been published in earlier articles [29-33]. The TSF is $8 \mathrm{~cm} \times 8 \mathrm{~cm}$ two-layer knitted fabric. In order to impart the sensing functionality, the fine metallic wires are seamlessly laid-in into the fibrous structure exactly in the middle of two layers as illustrated in Fig. 1 and Fig. 2. Two kinds of samples were fabricated on Shima Seiki electronic knitting machine i.e. 34 inlays and 46 inlays. The 34 inlays structure are inlaid with nearly $2.84 \mathrm{~m}$ of fine metallic wire while 46 inlays samples could able to embed around 3.86 of fine metallic wire (as sensing element). The TSF structure offers shield to the fine sensing element from the abrasion (hardly noticeable from each side and does not disrupt the appearance of the fabric). Various types of TSF samples were produced by the use of different varieties of sensing element such as enameled, braided and bare wire of Tungsten, Copper and Nickel in different diameters. The sensing principle of the TSF is the same as resistance thermometers (RTDs) i.e. metal's electrical resistance changes with temperature.

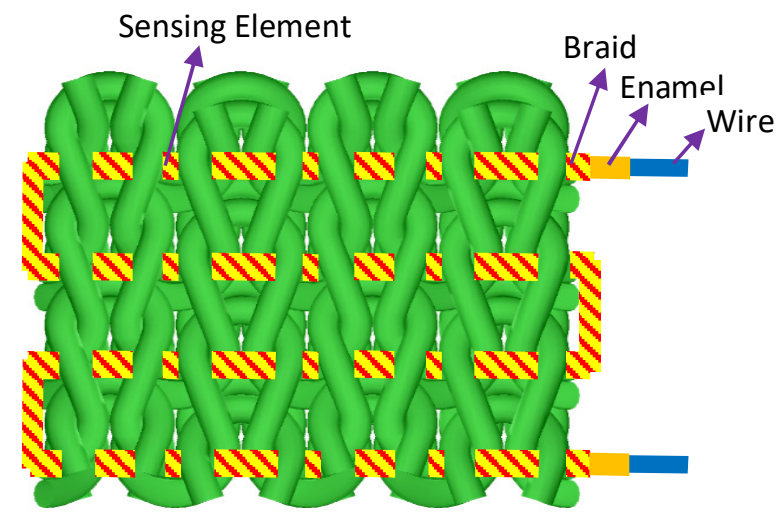

Fig. 1: An abstract graphic showing the insulated sensing element is being in-laid in the two layer structure of TSF

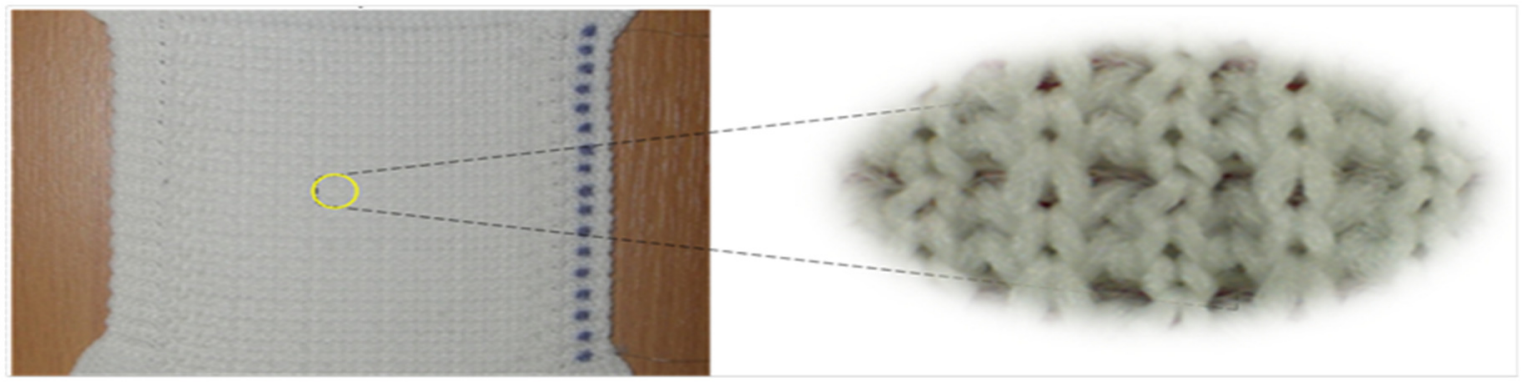

Fig. 2: A TSF sample of $8 \mathrm{~cm} \times 8 \mathrm{~cm}$ sensing region along with a microscopic view of the fabric structure

Mehran University Research Journal of Engineering and Technology, Vol. 41, No. 1, January 2022 [p-ISSN: 0254-7821, e-ISSN: 2413-7219] 
In order to investigate the effect of temperature on the resistance of sensing element and to develop the calibration equation, a dedicated test rig has been developed [31]. It is demonstrated in the literature review that the standard apparatus or procedure for the calibration of textile based temperature sensor has not been reported [31]. The test rig included a temperature-maintained hotplate, eight thermocouples, two copper plates, benchtop high resolution multimeter [34] and a temperature datalogger [35] as shown in Fig. 3. In order to measure the series of stable temperature and resistance values of TSF; uniform thermal environment was provided by the Copper plates to the TSF which is being sandwiched between the plates. The temperature profiles of the Copper plates are being measured by the thermocouples embedded in the copper plates. A high resolution benchtop multimeter was used to acquire the minute variations in the electrical resistance of sensing element of the TSF. The temperature of the TSF sensing element was determined by taking the average of temperature of both copper plates.

It has been discussed earlier [31] that the above test rig setting provided the stable uniform thermal environment to the TSF at fixed temperature of hotplate. The rig also provided the proficiency to precisely acquire the resistance and temperature parameters at these stable thermal condition [33]. To acquire and record the temperature-resistance data in a single interface, a LabVIEW based application has been created.

Validation of experimental results by mathematical modelling was one of the prime objectives of this study. This article explains the mathematical model of the rig components, developed under the steady state conditions, by the application of basic heat transfer principles. The components of the rig which were employed in modelling were a hotplate, a lower copper plate, the TSF, an upper copper plate and the environment. It was concluded that the temperature varies linearly across the TSF in test rig setting while the temperature of the sensing element can be calculated by knowing its exact position within the TSF. This information would help to calibrate the TSF samples in a better way and avoid the individual testing and repetition of experiments on a test rig.

\section{STEADY STATE MATHEMATICAL MODEL OF RIG COMPONENTS}

This section describes the one-dimensional steady state model of the rig components in terms of the application of basic heat transfer principles, so that

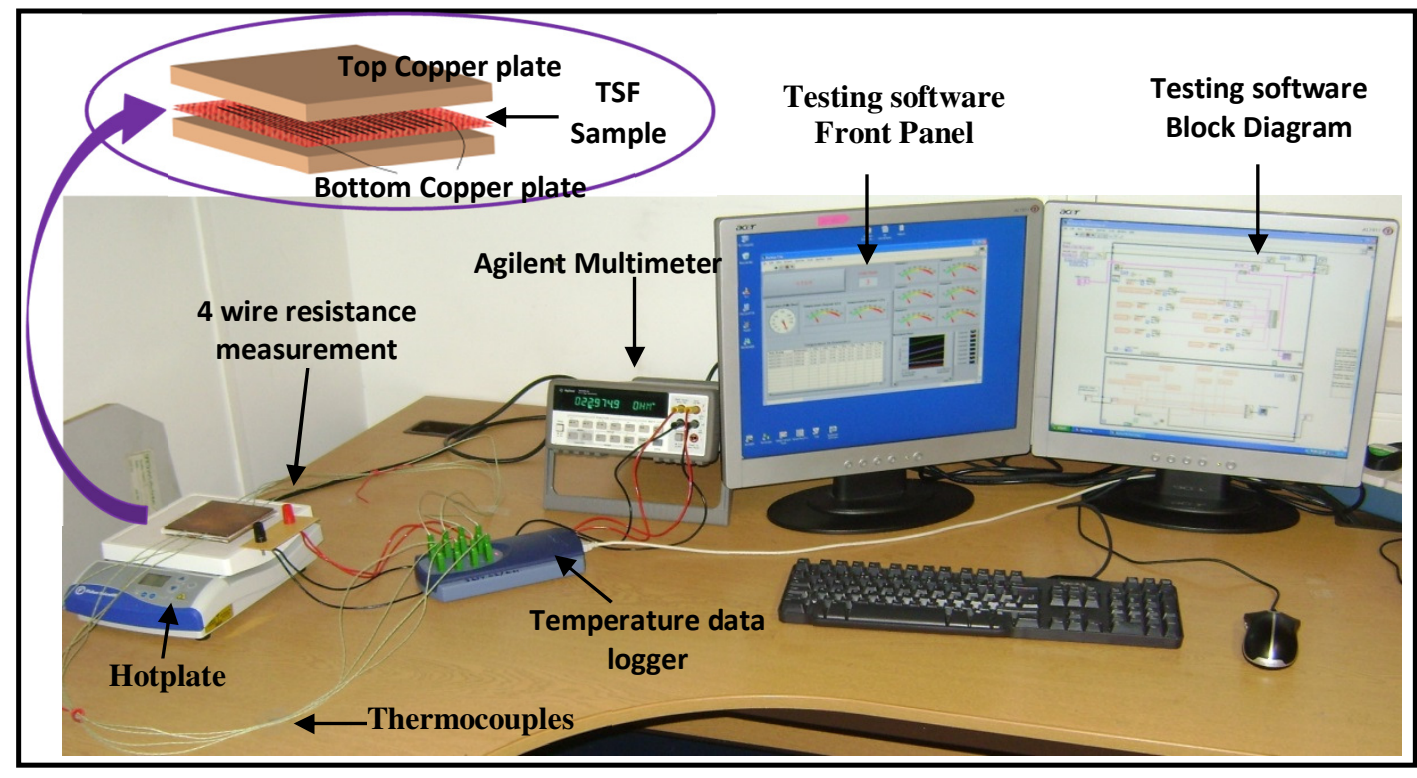

Fig. 3: Photograph of customized testing setup while in operation [29] 
the unknown information relating to temperature and thermal properties (thermal conductivity, coefficient of heat transfer etc.) of the rig components may be calculated. The steady state is a stable condition, when the temperature of rig components does not change over time. Fig. 4 presents a schematic diagram showing the rig components, important parameters associated with thermal modelling and the direction of heat flow. The top surface of the upper copper plate was exposed to convective heat transfer while the rest of the components all exchanged heat by conduction.

\subsection{Assumptions}

In order to develop an understanding, a simple model was created, with few assumptions incorporated. It was assumed that the hotplate was generating a constant heat flux so that the temperature of all the components was steady over time, as illustrated in Fig. 4. It was also assumed that the edges of the rig components were insulated so that heat was only allowed to flow from the hotplate to the environment through the rig components. In other words, there was no lateral heat transfer. All system components were assumed to be in perfect contact with each other, without any thermal contact resistance. The TSF was assumed to be a homogenous material and can be considered as one component.

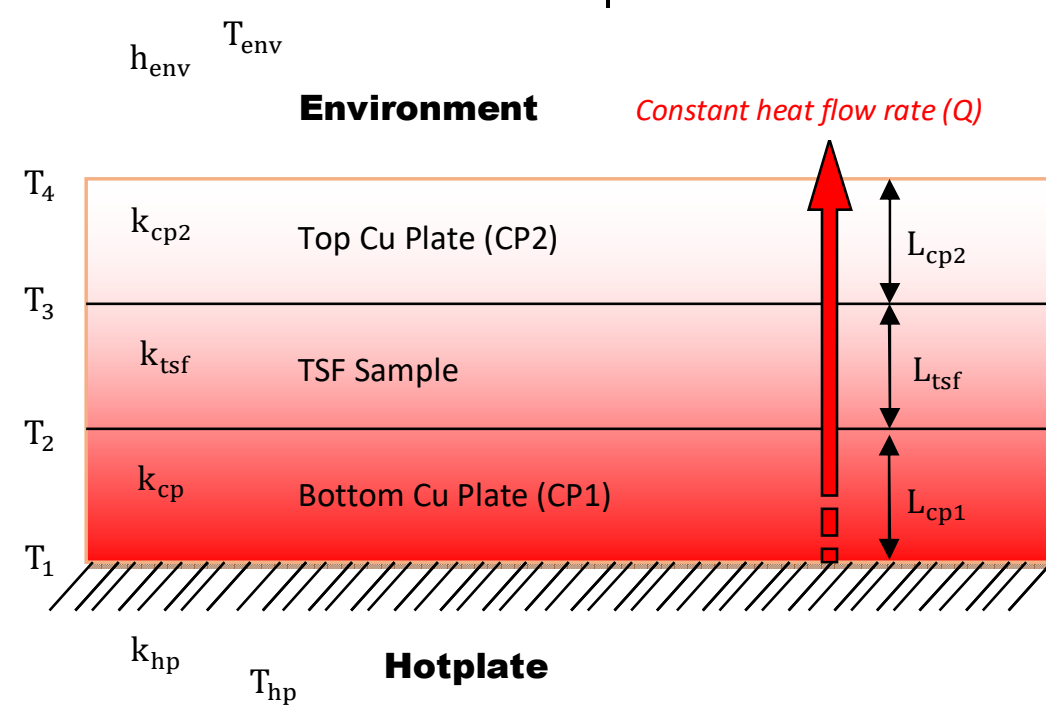

Fig. 4: Schematic diagram of heat flow through experimental rig

\subsection{Parameters and Equations}

List of the parameters and their description, used in the modelling are:

$\mathrm{Q} \rightarrow \quad$ Heat flow rate,

$\mathrm{T}_{1} \rightarrow \quad$ Temperature at the interface of hotplate and bottom $\mathrm{Cu}$ plate,

$\mathrm{T}_{2} \rightarrow$ Temperature at the interface of bottom $\mathrm{Cu}$ ' plate and TSF sample,

$\mathrm{T}_{3} \rightarrow \quad$ Temperature at the interface of TSF and top $\mathrm{Cu}$ plate,

$\mathrm{T}_{4} \rightarrow \quad$ Temperature at the interface of top $\mathrm{Cu}$ plate and environment,

$\mathrm{T}_{\text {hp }} \rightarrow$ Hotplate temperature,

$\mathrm{T}_{\text {env }} \rightarrow$ Room temperature,

$\mathrm{k}_{\mathrm{hp}}, \mathrm{k}_{\mathrm{cp} 1}, \mathrm{k}_{\mathrm{tsf}}, \mathrm{k}_{\mathrm{cp} 2} \rightarrow$ Thermal conductivities of hotplate, bottom copper plate, the TSF and top copper plate respectively,

$\mathrm{R}_{\mathrm{hp}}, \mathrm{R}_{\mathrm{cp} 1}, \mathrm{R}_{\mathrm{tsf}}, \mathrm{R}_{\mathrm{cp} 2,} \mathrm{R}_{\mathrm{env}} \rightarrow$ Thermal resistances of hotplate, bottom $\mathrm{Cu}$ plate, TSF, top $\mathrm{Cu}$ plate and environment respectively.

$\mathrm{L}_{\mathrm{cp} 1}, \mathrm{~L}_{\mathrm{tsf}} \mathrm{L}_{\mathrm{cp} 2} \rightarrow$ Thicknesses of bottom copper plate, the TSF and top copper plate respectively,

$\mathrm{h}_{\mathrm{env}} \rightarrow$ Convective heat transfer coefficient between top $\mathrm{Cu}$ plate and environment and,

$\mathrm{A} \rightarrow$ Surface area of $\mathrm{Cu}$ plates, TSF sample and hotplate.

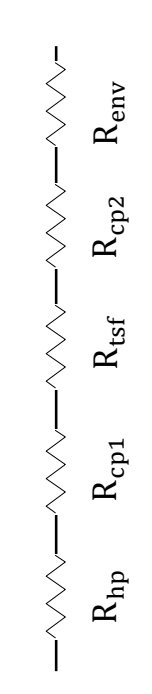


In order to develop expressions for unknown parameters, Fourier's law was applied across each component and Newton's law of cooling was applied at the interface of the top copper plate and the environment [36]. Since all the components were in the steady state, they can be compared in terms of heat flow $\operatorname{rate}(\mathrm{Q})$ as:

$\mathrm{Q}=\frac{\mathrm{k}_{\mathrm{cp} 1} \mathrm{~A}\left(\mathrm{~T}_{1}-\mathrm{T}_{2}\right)}{\mathrm{L}_{\mathrm{cp} 1}}=\frac{\mathrm{k}_{\mathrm{tsf}} \mathrm{A}\left(\mathrm{T}_{2}-\mathrm{T}_{3}\right)}{\mathrm{L}_{\mathrm{tsf}}}=\frac{\mathrm{k}_{\mathrm{cp} 2} \mathrm{~A}\left(\mathrm{~T}_{3}-\mathrm{T}_{4}\right)}{\mathrm{L}_{c p 2}}=$

$\mathrm{h}_{\text {env }} \mathrm{A}\left(\mathrm{T}_{4}-\mathrm{T}_{\text {env }}\right)$

The thermal resistance is the resistance of a material to the conduction or convection of thermal energy and is defined as:

$\mathrm{R}=\frac{\mathrm{L}}{\mathrm{kA}} \quad$ (For conduction)

$\mathrm{R}_{\mathrm{env}}=\frac{1}{\mathrm{~h}_{\mathrm{env}} \mathrm{A}} \quad$ (For convection)

Expression (1) can also be expressed in terms of thermal resistance as:

$Q=\frac{\left(T_{1}-T_{2}\right)}{R_{c p 1}}=\frac{\left(T_{2}-T_{3}\right)}{R_{\text {tcf }}}=\frac{\left(T_{3}-T_{4}\right)}{R_{c p 2}}=\frac{\left(T_{4}-T_{\text {env }}\right)}{R_{\text {env }}}$

Equation (4) can be rearranged as

$$
\begin{aligned}
\mathrm{Q} & =\frac{\left(\mathrm{T}_{1}-\mathrm{T}_{2}\right)}{\mathrm{R}_{\mathrm{cp} 1}}=\frac{\left(\mathrm{T}_{2}-\mathrm{T}_{3}\right)}{\mathrm{R}_{\mathrm{cp} 1}+\mathrm{R}_{\mathrm{tsf}}}=\frac{\left(\mathrm{T}_{1}-\mathrm{T}_{4}\right)}{\mathrm{R}_{\mathrm{cp} 1}+\mathrm{R}_{\mathrm{tsf}}+\mathrm{R}_{\mathrm{cp} 2}} \\
& =\frac{\left(\mathrm{T}_{1}-\mathrm{T}_{\text {env }}\right)}{\mathrm{R}_{\mathrm{cp} 1}+\mathrm{R}_{\mathrm{tsf}}+\mathrm{R}_{\mathrm{cp} 2}+\mathrm{R}_{\mathrm{env}}}
\end{aligned}
$$

\subsection{Known and Unknown Parameters}

In order to generate the linear calibration equation, it is important to find out the electrical resistance value of TSF at two temperature points. One point could be taken as the steady state room temperature before the start of the experiment. For second point, a thermal environment above the body temperature of human body $\left(37^{\circ} \mathrm{C}\right)$ was created with the help of $\mathrm{Cu}$ plates so that the body temperature could be accurately calculated when the calibrated sensor is used in the application environment.

Firstly, a sensing fabric sample sandwitched in the middle of two $\mathrm{Cu}$ plates was positioned on a hotplate. At this time all parts of the test rig had same temperature equivalent to the room temperature. The temperature-controlled hotplate (considering the temperature range of the intended application) was set in a manner to attain the approximate $45{ }^{\circ} \mathrm{C}$ steady temperature of the TSF. In the manner of step input, heat was applied to the rig parts from the surface of hotplate. The bottom $\mathrm{Cu}$ plate which was adjacent to hotplate surface, upon receiving the heat, increased its temperature instantaneously. The top $\mathrm{Cu}$ plate temperature also increased, however a slight delay is observed. After almost 40 min of transient state, all the rig components (hotplate surface, both $\mathrm{Cu}$ plates and TSF) reached to an approximate steady state.

In equation (4), the values of parameters; $\mathrm{T}_{1}, \mathrm{~T}_{4}, \mathrm{~T}_{\text {env }}, \mathrm{Q}, \mathrm{R}_{\mathrm{cp} 1}$ and $\mathrm{R}_{\mathrm{cp} 2}$, were known. The temperature parameters $\mathrm{T}_{1}$ (temperature at the interface of hotplate and bottom $\mathrm{Cu}$ plate) and $\mathrm{T}_{4}$ (temperature at the interface of top $\mathrm{Cu}$ plate and environment) were measured experimentally by the thermocouples fastened within the copper plates [31]. The environmental temperature $\left(\mathrm{T}_{\text {env }}\right.$ ) was measured using a RS Digital Hygro-Thermometer. The $R_{c p 1}$ and $R_{c p 2}$ were calculated by inserting the thermal conductivities and dimensions in equation (2).The dimensions of $\mathrm{Cu}$ plates were measured using a Vernier scale; while the TSF thickness was measured by the Feather Touch Digital Thickness Tester by SDL according to ASTM D1777 standard. The thermal conductivity of copper ( $\kappa_{\mathrm{cp} 1}$ and $\left.\kappa_{\mathrm{cp} 2}\right)$ is a universal parameters and taken as standard.

The heat flow rate $(\mathrm{Q})$ was calculated by measuring the power consumed by the hotplate at steady state; a power meter was employed for this purpose. The power consumed was measured by plugging the Power Meter into the mains socket and then plugging the Hotplate into the Power Meter. The hotplate employed in the rig was a constant temperature hotplate which tries to maintain its set temperature by switching its heating elements, on or off, automatically. Therefore it was important to measure the power for a known duration and take an average by dividing "the sum of all power values" for the "duration of the test". The 
average power required by the hotplate to maintain the rig components at steady state was found to be 3.68 watts. The average power (in watts) can be considered as the heat flow rate. The surface area of the hotplate and the copper plates were $240.25 \mathrm{~cm}^{2}$ and $81 \mathrm{~cm}^{2}$ respectively. This implies that the fraction of the hotplate area covered by the copper plate is only $33 \%$. Therefore, the heat flow passing through the rig components was calculated by multiplying the total heat flow of the hotplate by $33 \%$ i.e. 1.21 watts.

The values of known parameters found/calculated experimentally as explained above are:

$\mathrm{T}_{1}=49.25^{\circ} \mathrm{C} ; \quad \mathrm{T}_{4}=41.20^{\circ} \mathrm{C} ; \quad \mathrm{T}_{\mathrm{env}}=21^{\circ} \mathrm{C} ;$

$\mathrm{L}_{\mathrm{cp} 1}=\mathrm{L}_{\mathrm{cp} 2}=0.004 \mathrm{~m} ; \quad \mathrm{L}_{\mathrm{tsf}}=0.0035 \mathrm{~m}$;

$\mathrm{A}=9 \times 9 \mathrm{~cm}^{2}=0.0081 \mathrm{~m}^{2}$

$\mathrm{k}_{\mathrm{cp} 1}=\mathrm{k}_{\mathrm{cp} 2}=386 \mathrm{~W} / \mathrm{m}^{\circ} \mathrm{C}$

The unknown parameters may be derived from equation (4) and (5) as below:

$\mathrm{R}_{\mathrm{tsf}}=\frac{\left[\left(\mathrm{T}_{1}-\mathrm{T}_{4}\right)\right]-2 \mathrm{R}_{\mathrm{cp} 1} \mathrm{Q}}{\mathrm{Q}}$

$\mathrm{T}_{3}=\mathrm{T}_{1}-\mathrm{Q}\left(\mathrm{R}_{\mathrm{cp} 1}-\mathrm{R}_{\mathrm{tsf}}\right)$

$\mathrm{T}_{2}=\mathrm{T}_{1}-\left(\mathrm{R}_{\mathrm{cp} 1} \mathrm{Q}\right)$

$\mathrm{R}_{\mathrm{env}}=\frac{\left(\mathrm{T}_{1}-\mathrm{T}_{\mathrm{env}}\right)-\mathrm{Q}\left(2 \mathrm{R}_{\mathrm{cp} 1}+\mathrm{R}_{\mathrm{tsf}}\right)}{\mathrm{Q}}$

$\mathrm{h}_{\mathrm{env}}=\frac{1}{\mathrm{R}_{\mathrm{env}} \mathrm{A}}$

$\mathrm{k}_{\mathrm{tsf}}=\frac{\mathrm{L}_{\mathrm{tsf}}}{\mathrm{R}_{\mathrm{tsf}} \mathrm{A}}$

By inserting known parameters into equations (6) to (11); the values of unknown parameter were found to be:

$\mathrm{T}_{3}=41.202{ }^{\circ} \mathrm{C}$

$\mathrm{T}_{2}=49.248^{\circ} \mathrm{C}$

$\mathrm{R}_{\mathrm{tsf}}=0.054 \mathrm{~m}^{2}{ }^{\circ} \mathrm{C} / \mathrm{W}$
$\mathrm{K}_{\text {tsf }}=0.0650 \mathrm{~W} / \mathrm{m}^{\circ} \mathrm{C}$
$\mathrm{R}_{\text {env }}=0.135 \mathrm{~m}^{2}{ }^{\circ} \mathrm{C} / \mathrm{W}$
$\mathrm{h}_{\mathrm{env}}=7.34 \mathrm{~W} / \mathrm{m}^{2}{ }^{\circ} \mathrm{C}$

\subsection{Estimation of Temperature of Sensing Element}

Assuming that TSF is a homogenous material whose temperature changes with respect to its thickness $(\mathrm{T}=$ $f(x))$ as shown in Fig. 5.

Applying Fourier's law across the TSF [36], would yield:

$\frac{\mathrm{Q}}{\mathrm{A}}=-\mathrm{k} \frac{\mathrm{dT}}{\mathrm{dx}}$

$\frac{\mathrm{Q}}{\mathrm{A}} \mathrm{dx}=-\mathrm{kdT}$

The minus sign indicates the decrease in temperature as heat flows towards the positive $\mathrm{x}$-direction. Now, suppose that the temperature of the underside of the TSF is indicated by $T_{2}$ when $x=0$. Similarly $T_{3}$ represents the temperature of the upper side of the TSF when $\mathrm{x}=\mathrm{L}_{\mathrm{tsf}}$. After integrating both sides of equation (13) with the limits of $\mathrm{x}=0 \rightarrow \mathrm{L}_{\mathrm{tsf}}$ and $\mathrm{T}=\mathrm{T}_{2} \rightarrow \mathrm{T}_{3}$ the result is:

$\frac{\mathrm{Q}}{\mathrm{A}}=\frac{\mathrm{k}}{\mathrm{L}_{\mathrm{tsf}}}\left(\mathrm{T}_{2}-\mathrm{T}_{3}\right)$

Assuming that $T$ is the temperature at a certain distance $\mathrm{x}$ from the underside of the TSF. After integrating equation (13) again between the limits of $\mathrm{x}=0 \rightarrow \mathrm{L}$ and $\mathrm{T}=\mathrm{T}_{2} \rightarrow \mathrm{T}$ the result is:

$\frac{\mathrm{Q}}{\mathrm{A}}=\frac{\mathrm{k}}{\mathrm{L}}\left(\mathrm{T}_{2}-\mathrm{T}\right)$

Now comparing equation (14) and (15) and ruling out

Constant heat flow rate $(\mathrm{Q})$

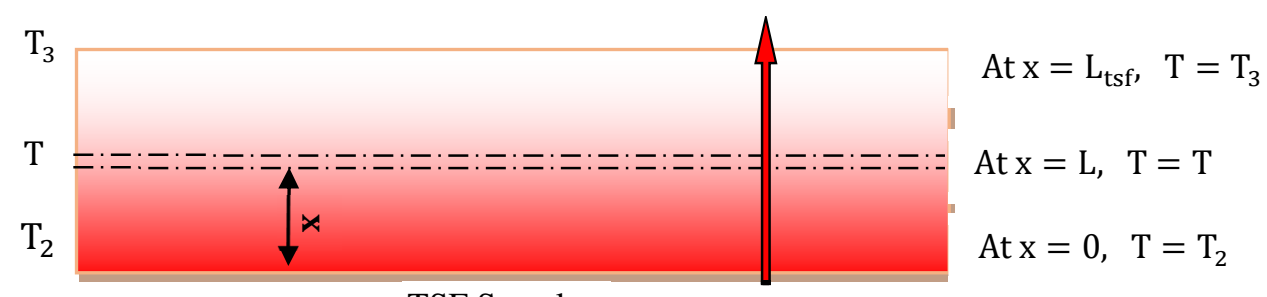

TSF Sample

Fig. 5: Change in Temperature across the thickness of TSF as homogenous material 
the factor of $(\mathrm{Q} / \mathrm{A})$, the temperature $(\mathrm{T})$ of the TSF at a certain thickness (L) can be expressed as:

$\mathrm{T}=\mathrm{T}_{2}-\frac{\mathrm{L}\left(\mathrm{T}_{2}-\mathrm{T}_{3}\right)}{\mathrm{L}_{\mathrm{tsf}}}$

\section{RESULTS AND DISCUSSION}

The temperature drops across the components: i.e. $0.02{ }^{\circ} \mathrm{C}$ across the lower copper plate, $0.02{ }^{\circ} \mathrm{C}$ across the upper copper plate, and $8.04{ }^{\circ} \mathrm{C}$ across the TSF, indicates that there was hardly any temperature difference across the copper plates. However, a large gradient of temperature was observed across the TSF. This can also relate with the low Biot number of the copper plates and high Biot number of the TSF. The Biot number is a dimensionless parameter, usually used to classify the component as lumped or not, and can be defined as:

$B=\frac{h L}{k}$

Where $\mathrm{h}$ and $\mathrm{k}$ represents the convective heat transfer coefficient at the surface of the component and its thermal conductivity. While $\mathrm{L}$ is the characteristic length of the component, defined as the ratio of volume and surface area of the component.

When the Biot number of a component is less than 0.1, then the inside component temperature will be the same and the dominant temperature difference will be at the surface. In this case the component may be considered as "Lumped" or "Thermally Thin". On the contrary, a component, having a Biot number greater than 0.1 may be considered as "Non-Lumped" or "Thermally Thick". Because of the high thermal conductivity and small thickness, the Biot number of the copper plates was found to be much lower than 0.1 . This was also evident from the temperature drop across the copper plates $\left(<0.02^{\circ} \mathrm{C}\right)$. This means that copper plates may be considered as being lumped.

Equation (16) describes that the temperature between $\mathrm{T}_{2}$ and $\mathrm{T}_{3}$ varies linearly. This means that the temperature of the sensing element can be calculated by knowing its exact position within the TSF. Since the sensing element was inlaid exactly in the middle of a double layer TSF, its temperature value could be calculated $\left(\mathrm{T}_{\mathrm{SE}}=45.225^{\circ} \mathrm{C}\right)$ by inserting half of the thickness $(\mathrm{L}=1.75 \mathrm{~mm}$ ) in equation (16) . It is important to note here that this equation can only be applied on homogeneous material having uniform (k) value over its entire thickness. Now the modelled $\mathrm{T}_{\mathrm{SE}}$ value is almost the same as the experimental $\mathrm{T}_{\mathrm{SE}}$ value at a certain temperature of the upper and lower copper plates. This is because the assumption behind the modelling and the experimental estimate were the same i.e. the Temperature changes linearly across the thickness of the TSF.

The thermal conductivity of the TSF $\left(\mathrm{K}_{\mathrm{tsf}}\right)$ and the convective coefficient $\left(h_{e n v}\right)$ are quite reasonable values considering the assumption of the model. However it is more appropriate to measure $h_{e n v}$ and $\mathrm{k}_{\mathrm{TSF}}$ experimentally and then use them in this model for more accurate results.

\subsection{Model Limitations}

The expressions stated earlier can only be applied when:

- all components of the rig are in the steady state i.e. there is no change in temperature with respect to time;

- heat transfer occurs in only one direction;

- TSF is considered to be homogenous material.

In order to validate the TSF/test rig results in a transient conditions, a Lumped Capacitance Method (LCM) can be applied to resolve this issue in a simplified way. In this approach the TSF may be converted into small sub-components and solved by first arranging them in close approximation to the actual structure and by then applying basic heat transfer principles. However this is beyond the scope of this work and would be discussed in a separate study.

\section{CONCLUSION}

A standard mathematical model of rig components, 
developed under the steady state conditions, by the application of basic heat transfer principles is presented in this article. The rig components are used to calibrate the samples of Temperature-SensingFabric (TSF). Once calibrated, these samples could be used in the practical environment. It was concluded that the temperature varies linearly across the TSF in test rig setting while the temperature of the sensing element can be calculated by knowing its exact position within the TSF. Since the sensing element was inlaid in the middle of double layer TSF, its temperature value could be calculated by inserting half of the thickness in the developed equation. It is important to note that the equation is valid only for one dimensional steady state heat flow transfer; and for homogeneous material having uniform thermal conductivity of fabric over its entire thickness. This information would help to calibrate the TSF samples in a better way and avoid the individual testing and repetition of experiments on a test rig.

\section{ACKNOWLEDGEMENT}

The authors would like to acknowledge the funding provided by the NED University of Engineering \& Technology, Pakistan through the Higher Education Commission of Pakistan, to carry out this study.

\section{REFERENCES}

1. Sayem A. S. M., Teay S. H., Shahariar H., Fink P. L., Albarbar A., "Review on Smart ElectroClothing Systems (SeCSs)", Sensors, Vol. 20, No. 3, 2020.

2. Lina M. C., Alison B. F., "Smart fabric sensors and e-textile technologies: a review", Smart Materials and Structures, Vol. 23, No. 5, 2014.

3. Liu Y., Wang H., Zhao W., Zhang M., Qin H., Xie Y., "Flexible, Stretchable Sensors for Wearable Health Monitoring: Sensing Mechanisms, Materials, Fabrication Strategies and Features", Sensors, Vol. 18, No. 2, p. 645, 2018.

4. Tang S.L.P., "Recent developments in flexible wearable electronics for monitoring applications," Transactions of the Institute of Measurement and Control, Vol. 29, nBo. 3-4, pp. 283-300, 2007.
5. Ismar E., Bahadir S.K., Kalaoglu F., Koncar V., "Futuristic Clothes: Electronic Textiles and Wearable Technologies", Global Challenges, Vol. 4, No. 7, 2020.

6. Mokhtari F., Cheng Z., Raad R., Xi J., Foroughi J., "Piezo fibers to smart textiles: a review on recent advances and future outlook for wearable technology", Journal of Materials Chemistry A, Vol. 8, No. 19, pp. 9496-9522, 2020.

7. Funnell R., Koutoukidis G., Lawrence K., "Chapter 21 - Vital Signs", In Tabbner's Nursing Care: Theory and Practice”, pp. 251274.Churchill Livingstone, Sydney, Australia: 2009.

8. Parsons K., "Human thermal physiology and thermoregulation" in Human Thermal Environments: Taylor and Francis, pp. 31-48, 2003.

9. Jardine D. S., "Heat Illness and Heat Stroke", Pediatrics in Review, Vol. 28, No. 7, pp. 249-258, July 2007.

10. Paul G., Torah R., Beeby S., Tudor J., "Novel active electrodes for ECG monitoring on woven textiles fabricated by screen and stencil printing," Sensors and Actuators A: Physical, Vol. 221, pp. 60-66, 2015.

11. Xie J., Long H., "Equivalent resistance calculation of knitting sensor under strip biaxial elongation", Sensors and Actuators A: Physical, Vol. 220, pp. 118-125, 2014.

12. Atalay O., Kennon W., Husain M., "TextileBased Weft Knitted Strain Sensors: Effect of Fabric Parameters on Sensor Properties", Sensors, Vol. 13, No. 8, pp. 11114-11127, 2013.

13. Chang W. Y., Fang T. H., Lin Y. C., "Characterization and fabrication of wireless flexible physiological monitor sensor", Sensors and Actuators A: Physical, Vol. 143, No. 2, pp. 196-203, 2008.

14. Cheng M. H., Chen L. C., Ying-Che H., Ming Y.C., , Lin Y.T., "A Real-Time Heart-Rate Estimator from Steel Textile ECG Sensors in a Wireless Vital Wearing System", Proceedings of the 2nd International Conference on Bioinformatics and Biomedical Engineering, pp. 1339-1342, Shanghai, China, 16-18 May 2008.

15. Paradiso R., Pacelli M., Loriga G., "Flat Knitted 
Sensors for Respiration Monitoring", Proceedings of the IEEE International Symposium on Industrial Electronics, pp. 28382841, Vigo, Spain, 4-7 June 2007.

16. Catrysse M., Puers R., Hertleer C., Van Langenhove L., Van Egmond H., Matthys D., "23", Sensors and Actuators A: Physical, Vol. 114, No. 2-3, pp. 302-311, 2004.

17. Kannaian T., Neelaveni R., Thilagavathi G., "Design and development of embroidered textile electrodes for continuous measurement of electrocardiogram signals", Journal of Industrial Textiles, Vol. 42, No. 3, pp. 303-318, January 2013.

18. Curone D., Dudnik G., Loriga G., Magenese G., Secco E.L., Tognetti Aonfiglio A., "Smart garments for emergency operators: results of laboratory and field tests", Proceedings of the Annual International Conference of IEEE Engineering in Medicine and Biology Society, pp. 494-497, Vancouver, British Columbia, Canada, 20-25 August, 2008.

19. Derchak P.A., Ostertag K. L., Coyle M.A., "LifeShirt ${ }^{\circledR}$ System as a monitor of heat stress and dehydration", 2004.

20. Noury N., Dittmar A., Corroy C., Baghai R., Weber J.L., Blanc D., Klefstat F., Blinovska A., Vaysse S., Comet B., "VTAMN - A Smart Clothe for Ambulatory Remote Monitoring of Physiological Parameters and Activity", Proceedings of the 26th Annual International IEEE Engineering in Medicine and Biology Society (EMBS) Conference, San Francisco, California, 1-4 September 2004. .

21. Pandian P. S., Mohanavelu K., Safeer K.P., Kotresh T.M., Shakunthala D.T., Gopal P., Padaki V.C., "Smart Vest: Wearable multi-parameter remote physiological monitoring system", Medical Engineering and Physics, Vol. 30, pp. 466-477, 2008.

22. Hughes-Riley T., Lugoda P., Dias T., Trabi C., Morris R., "A Study of Thermistor Performance within a Textile Structure", Sensors, Vol. 17, No. 8, 2017.

23. Ziegler S., Frydrysiak M., "Initial Research into the Structure and Working Conditions of Textile Thermocouple", Fibers and Textiles in Eastern
Europe, Vol. 17, No. 6, pp. 84-88, 2010.

24. Bielska S., Sibinski M., Lukasik A., "Polymer temperature sensor for textronic applications," Materials Science and Engineering: B, Vol. 165, No. 1, pp. 50-52, 2009.

25. De Rossi D., Santa A.D., Mazzoldi A., "Dressware: wearable hardware", Materials Science and Engineering: C, Vol. 7, No. 1, pp. 3135, 1999.

26. Locher I., Kirstein T., Troester G., "Routing Methods Adapted to e-Textiles", Proceedings of the 37th International Symposium on Microelectronics (IMAPS 2004), Long Beach CA, 2004.

27. Locher I., Kristein T., Troes G., "Temperature profile estimation with smart textiles", Proceedings of the International Conference on Intelligent Textiles, Smart Clothing, Well-being and Design, Tampere, Finland, 19 - 20 September 2005.

28. Sibinski M., Jakubowska M., Sloma M., "Flexible Temperature Sensors on Fibers," Sensors, Vol. 10, No. 9, pp. 7934-7946, 2010.

29. Husain M. D., Kennon W. R., Dias T., "Design and Fabrication of Temperature Sensing Fabric", Journal of Industrial Textiles, Vol. 44, No. 3, pp. 398-417, 2014.

30. Husain M. D., Atalay O., Kennon W. R., "Effect of Strain and Humidity on the Performance of Temperature Sensing Fabric", International Journal of Textile Science, Vol. 2, No. 4, pp. 105112, 2013.

31. Husain M. D., Atalay O., Atalay A., Kennon W. R., "Development of Test Rig System for Calibration of Temperature Sensing Fabric", AUTEX Research Journal, Vol. 17, No. 3, pp. 219-228, 2017.

32. Husain M. D., Naqvi S., Atalay O., Hamdani S. T. A., Kennon R., "Measuring Human Body Temperature through Temperature Sensing Fabric", AATCC Journal of Research, Vol. 3, No. 4, pp. 1-12, 2016.

33. Husain M., Atalay O., Atalay A., Kennon R., "Uncertainty Analysis of the TemperatureResistance Relationship of Temperature Sensing Fabric", Fibers, Vol. 4, No. 4, 2016.

34. Agilent Technologies, (08-11-2019). Agilent 
34401 M Multimeter - Product Overview.

Available:

http://cp.literature.agilent.com/litweb/pdf/59680162EN.pdf [Last accessed on $15^{\text {th }}$ July 2020].

35. PicoTech, "USB TC-08 Thermocouple Data Logger". Available at:

http://www.picotech.com/thermocouple.html [Last accessed on 16th July 2020].

36. Cengel Y. A., "Chapter 3 - Steady Heat Conduction", in Heat Transfer: A Practical Approach: McGraw-Hill, pp. 127-208, 2003. 